\title{
Leap Zagreb Connection Numbers for Some Networks Models
}

\author{
Zahid Raza \\ Department of Mathematics, University of Sharjah, University City, P.O. Box. 27272, Sharjah, United Arab Emirates
}

\section{* Corresponding author:}

tel: $+971-568053219$

email: zraza@sharjah.ac.ae

Received: January 13, 2020

Accepted: March 24, 2020

DOI: $10.22146 / \mathrm{ijc} .53393$

\begin{abstract}
The main object of this study is to determine the exact values of the topological indices which play a vital role in studying chemical information, structure properties like QSAR and QSPR. The first Zagreb index and second Zagreb index are among the most studied topological indices. We now consider analogous graph invariants, based on the second degrees of vertices, called leap Zagreb indices. We compute these indices for Tickysim SpiNNaker model, cyclic octahedral structure, Aztec diamond and extended Aztec diamond.
\end{abstract}

Keywords: Zagreb connection indices; Tickysim SpiNNaker model; cyclic octahedral; Aztec and extended Aztec diamond

\section{- INTRODUCTION}

Chemical graph theory is an interdisciplinary field of science which relates chemistry with a branch of mathematical modeling of graphs. In this area of math, one deals with topology of physical structure of a molecule to understand chemical properties of the compounds. A small but significant part of this field is the topic known as topological index where a molecular structure of a chemical formula is scientifically constructed to predict physical and chemical properties of certain molecule. First kind topological index was introduced in 1947 by Wiener. The topological graph is built on atoms as vertices (except for hydrogen atoms and bonds that are always ignored and not considered) and bonds connecting two atoms as edges. There are many different types of topological indices that have been known to exist with vast literature based on them, see for example [5-6,12-14,18-21].

The first Zagreb Index, occurred in an approximate formula for the total $\pi$-electron energy [1] and the second Zagreb Index appeared within the study of molecular branching [9]. The first Zagreb connection index and second Zagreb connection index, $\mathrm{ZC}_{1}$ and $\mathrm{ZC}_{2}$ respectively, have been put forward in [10] and [11] independently. It has been proved in [10] that the topological index $\mathrm{ZC}_{1}$ can be written in the form given in Eq. (1). Then Basavanagoud and Praveen Jakkannavar has checked the chemical applicability of $\mathrm{ZC}_{1}$ and have found that the index has a very good correlation with physical properties of chemical compounds like boiling point, entropy, enthalpy of evaporation, standard enthalpy of vaporization and acentric factor [15] The authors in Ref [10] checked the chemical applicability of $\mathrm{ZC}_{1}$ and they found that this topological index correlates well with the entropy and acentric factor of octane isomers. Recently, extremal chemical trees with fixed segment length or vertices of degree 2 with respect to modified first Zagreb connection index has been given in Ref. [16] and further extended to general $n$ - vertex tree in [17]. The authors in Ref [2-3] determined some degree base topological indices for diamond like networks and Tickysim SpiNNaker model sheet.

The first connection and second connection index were introduced in 1972 and 1975, respectively. Third connection index is relatively new. These indices are defined as follows for any graph $\mathrm{G}$ of order $\mathrm{n}$ :

$$
\begin{aligned}
& \mathrm{ZC}_{1}(\mathrm{G})=\sum_{0 \leq \mathrm{i} \leq \mathrm{n}-2} \mathrm{c}_{\mathrm{i}}(\mathrm{G})^{* \mathrm{i}^{2}} \\
& \mathrm{ZC}_{1}(\mathrm{G})=\sum_{0 \leq \mathrm{i} \leq \mathrm{n}-2} \mathrm{c}_{\mathrm{i}}(\mathrm{G})^{*}{ }^{2}{ }^{2} \\
& \mathrm{ZC}_{1}^{*}(\mathrm{G})=\sum_{0 \leq \mathrm{i} \leq \mathrm{j} \leq \mathrm{n}-2} \mathrm{y}_{\mathrm{i}, \mathrm{j}}(\mathrm{G})^{*}(\mathrm{i}+\mathrm{j})
\end{aligned}
$$

Here $V(G)$ is the vertex set of graph $G, E(G)$ is edge set of graph $\mathrm{G}$. The $\mathrm{c}_{\mathrm{i}}$ denotes the vertex with connection number $\mathrm{i}$ and $\mathrm{y}_{\mathrm{i}, \mathrm{j}}$ denotes the number of edges with 
connection number $i$ and $j$. We do not deal with degree of the vertices here so connection number is not to be mistaken with degree of the vertex.

\section{Tickysim SpiNNaker Model}

A hexagonal torus that has $m$ vertices in row and $n$ vertices in columns with vertices with total of $m n$ vertices and number of edges equal to $3 m n-2 n-2 m+1$. The second of the network topology consists of a set of a hexagonal segments of a hexagonal mesh of nodes. Each node in the simulation represents a SpiNNaker chip that contains a router, packet generator, packet consumer, and a tree of two-input round-robin arbiters which arbitrates between the inputs to the router. The router always consists of a four-stage pipeline. If a packet cannot be forwarded to its requested output after 50 cycles at the head of the router, it is dropped. The packet generator generates packets for each node of the system. If the output buffer is full, the packet generator waits until a space becomes available. The packet consumer receives incoming packets immediately, but the packet consumer will wait 10 cycles before accepting another packet. The arbiter tree is based on SpiNNaker's NoC aspects. In each cycle, the arbiter selects a waiting packet on one of its inputs and forwards it to its output if there is space in the output buffer. For more details, see [4]. The graph TSM sheet is shown in Fig. 1.

\section{Cyclic Octahedral Structure}

The Platonic solid known as octahedron with six vertices and 12 edges. An octahedron graph, is a polyhedral graph corresponding to the skeleton of the octahedron, one of the five Platonic solids. The analogy of this structure play vital roles in the field of reticular chemistry, which deals with the synthesis and properties of metal-organic frameworks [7-8]. The different types of octahedral structures arise from the ways that these octahedral can be connected. The cyclic octahedral structure of dimension $\mathrm{n}$ is denoted by $\mathrm{CYO}(\mathrm{n})$, and it is obtained by arranging $\mathrm{n}$ octahedra in cyclic order, as shown in Fig. 2. The cyclic octahedral structure CYO(n) consists of $5 n$ vertices and $12 n$ edges for $n>2$.

\section{Aztec Diamond}

A diamond shaped graph(see Fig. 3) with insides resembling a domino like structure, is built on square lattices with a vertex in the center of the graph considered as the origin on the $\mathrm{x}, \mathrm{y}$ plane with half integers taken for $\mathrm{x}$ and $\mathrm{y}$.

\section{Extended Aztec Diamond}

Extended Aztec diamond (see Fig. 4) is the exact shape and structure as the Aztec diamond but the outer vertices are conjoined by extra edges.

\section{- RESULTS AND DISCUSSION}

The In this section we will present our main results of this paper. In particularly, we compute the leap Zagreb



Fig 1. Graph of the TSM sheet for $m=10$ and $n=8$



Fig 2. Cyclic octahedral structure (CYO8)

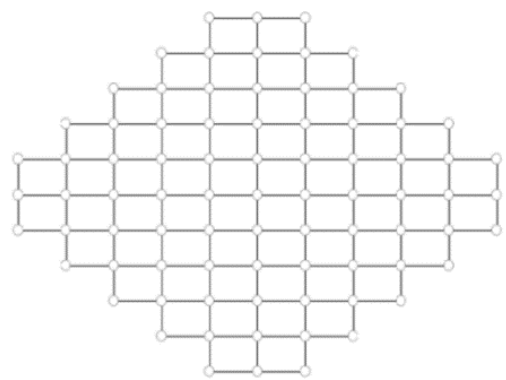

Fig 3. Aztec diamond $A Z D(n)$ 




Fig 4. Extended Aztec diamond EAZD(n)

indices of TSM sheet, cyclic octahedral structure, Aztec diamond and extended Aztec diamond and findings presented in this section.

\section{Theorem 1}

Let TSM be the graph of Tickysim SpiNNaker model, for $n, m \geq 5$. Then the Zagreb connection indices for the TSM are given as:

(1) $\mathrm{ZC}_{1}(\mathrm{TSM})=670+144 \mathrm{mn}-316[\mathrm{n}+\mathrm{m}]$

(2) $\mathrm{ZC}_{2}(\mathrm{TSM})=2600+432 \mathrm{mn}-1072[\mathrm{n}+\mathrm{m}]$

(3) $\mathrm{ZC}_{1}^{*}(\mathrm{TSM})=198+72 \mathrm{mn}-124[\mathrm{n}+\mathrm{m}]$

\section{Proof}

We know the general connection index is $Z_{1}(G)=\sum_{0 \leq i \leq n-2} c_{i}(G)^{*} \dot{i}^{2}$. Taking into account the restriction that $n \geq 5$ and $m \geq 5$, we have the following connection numbers for the TSM sheet. On two diagonal corner ends the connection number $c_{3}$ is fixed as the number of vertices from it with distance two are 3 . Also, the opposite end corners $c_{5}$ is fixed. Where $c_{3}$ is always flanked by $c_{4} s$ on its two on outer surface, $c_{5}$ is flanked by $c_{6}$ on both outer surface. As $m$ and $n$ increase so do the $c_{7}$ on the border between $c_{4}$ and $c_{6}$.

Therefore $c_{3}, c_{4}, c_{5}, c_{6}$ are fixed and $c_{7}$ on outer border is given as;

$\mathrm{c}_{7}=2(\mathrm{n}-4)+2(\mathrm{~m}-4), \mathrm{c}_{3}=2, \mathrm{c}_{4}=4, \mathrm{c}_{5}=2, \mathrm{c}_{6}=6$.

Moving into the inner parallelogram $c_{9}$ that increase with the vertices $n, m$. Hence; $c_{9}=2(n-4)+2(m-4)$.

Finally the innermost graph has vertices all the same connection number 12 . To have a $\mathrm{c}_{12}$ vertex should have at least 2 vertices above it, below it, to its left and to its right. Therefore; $c_{12}=(n-4)(m-4)$.
We know the general connection index is given by $\mathrm{ZC}_{1}(\mathrm{TSM})=\sum_{0 \leq \mathrm{i} \leq \mathrm{n}-2} \mathrm{C}_{\mathrm{i}}(\mathrm{G})^{*} \mathrm{i}^{2}$, and from vertex partition given in Table 1 , we have

$$
\begin{aligned}
\mathrm{ZC}_{1}(\mathrm{TSM})= & \sum_{0 \leq \mathrm{i} \leq \mathrm{n}-2} \mathrm{c}_{\mathrm{i}}(\mathrm{G}) *^{{ }^{2}}=2.3^{2}+4.4^{2}+2.5^{2}+6.6^{2} \\
& +(2 \mathrm{n}+2 \mathrm{~m}-14) 7^{2}+(2 \mathrm{n}+2 \mathrm{~m}-16) 9^{2} \\
& +(\mathrm{mn}-4 \mathrm{n}-4 \mathrm{~m}+16) 12^{2} \\
= & 18+64+50+216+49(2 \mathrm{n}+2 \mathrm{~m}-14) \\
& +81(2 \mathrm{n}+2 \mathrm{~m}-16)+144(\mathrm{~nm}+16-4 \mathrm{n}-4 \mathrm{~m})
\end{aligned}
$$

After simplification of terms, we get put required formula for the connection number for TSM sheet.

$\mathrm{ZC}_{1}(\mathrm{TSM})=670+144 \mathrm{mn}-316[\mathrm{n}+\mathrm{m}]$

For the indices $\mathrm{ZC}_{2}(\mathrm{TSM})$ and $\mathrm{ZC}_{1}^{*}(\mathrm{TSM})$, we need to partition the edges of the TSN sheet according to the connection numbers of the end points of an edge. It is easy to see that all the edges labelled with their connection number are given in Table 2.

Table 1. Partition of vertex set of TSM sheet

\begin{tabular}{ll}
\hline Vertices of type $c_{i}$ & Number of vertices \\
\hline$c_{3}$ & 2 \\
$c_{4}$ & 4 \\
$c_{5}$ & 2 \\
$c_{6}$ & 6 \\
$c_{7}$ & $2 n+2 m-14$ \\
$c_{9}$ & $2 n+2 m-16$ \\
$c_{12}$ & $m n-4 n-4 m+16$ \\
\hline
\end{tabular}

Table 2. Partition of edge set of TSM sheet

\begin{tabular}{ll}
\hline Edges of type $\mathrm{y}_{\mathrm{i}, \mathrm{j}}($ TSM $)$ & Number of edges \\
\hline $\mathrm{y}_{3,4}$ & 4 \\
$\mathrm{y}_{4,4}$ & 2 \\
$\mathrm{y}_{4,6}$ & 4 \\
$\mathrm{y}_{4,7}$ & 4 \\
$\mathrm{y}_{5,6}$ & 4 \\
$\mathrm{y}_{5,7}$ & 2 \\
$\mathrm{y}_{6,7}$ & 12 \\
$\mathrm{y}_{6,9}$ & 8 \\
$\mathrm{y}_{7,7}$ & $2 \mathrm{~m}+2 \mathrm{n}-10$ \\
$\mathrm{y}_{7,9}$ & $4 \mathrm{~m}+4 \mathrm{n}-32$ \\
$\mathrm{y}_{7,12}$ & 2 \\
$\mathrm{y}_{9,9}$ & $2 \mathrm{~m}+2 \mathrm{n}-18$ \\
$\mathrm{y}_{9,12}$ & $4 \mathrm{~m}+4 \mathrm{n}-36$ \\
$\mathrm{y}_{12,12}$ & $3 \mathrm{mn}-14 \mathrm{~m}-14 \mathrm{n}+65$ \\
\hline
\end{tabular}


From Eq. (2) and Table 2, we have the followings:

$$
\begin{aligned}
\mathrm{ZC}_{2}(\mathrm{TSM})= & \sum_{0 \leq \mathrm{i} \leq \mathrm{n}-2} \mathrm{y}_{\mathrm{i}, \mathrm{j}}(\mathrm{TSM})^{\star_{\mathrm{ij}}} \\
\mathrm{ZC}_{2}(\mathrm{TSM})= & \mathrm{y}_{3,4}(3)(4)+\mathrm{y}_{4,4}(4)(4)+\mathrm{y}_{4,6}(4)(6) \\
& +\mathrm{y}_{4,7}(4)(7)+\mathrm{y}_{5,6}(5)(6)+\mathrm{y}_{5,7}(5)(7) \\
& +\mathrm{y}_{6,7}(6)(7)+\mathrm{y}_{6,9}(6)(9)+\mathrm{y}_{7,7}(7)(7) \\
& +\mathrm{y}_{7,9}(7)(9)+\mathrm{y}_{7,12}(7)(12)+\mathrm{y}_{9,9}(9)(9) \\
& +\mathrm{y}_{9,12}(9)(12)+\mathrm{y}_{12,12}(12)(12) \\
= & 12(4)+16(2)+24(4)+28(4)+30(4)+35(2) \\
& +42(12)+54(8)+49(2 \mathrm{~m}+2 \mathrm{n}-10)+63(4 \mathrm{~m} \\
& +4 \mathrm{n}-32)+84(2)+81(2 \mathrm{~m}+2 \mathrm{n}-18)+108(4 \mathrm{~m} \\
& +4 \mathrm{n}-36)+144(3 \mathrm{mn}-14 \mathrm{~m}-14 \mathrm{n}+65)
\end{aligned}
$$

After simplification of terms, we get the required formula for TSM as:

$$
\begin{aligned}
\mathrm{ZC}_{2}(\mathrm{TSM})= & 2600+432 \mathrm{mn}-1072[\mathrm{n}+\mathrm{m}] \\
\text { From Eq. } & (3) \text { and Table } 2 \text { we have } \\
\mathrm{ZC}_{1}^{*}(\mathrm{TSM})= & \sum_{0 \leq \mathrm{i} \leq \mathrm{n}-2} \mathrm{y}_{\mathrm{i}, \mathrm{j}}(\mathrm{TSM})^{*}(\mathrm{i}+\mathrm{j}) \\
\mathrm{ZC}_{1}^{*}(\mathrm{TSM})= & \mathrm{y}_{3,4}(3+4)+\mathrm{y}_{4,4}(4+4)+\mathrm{y}_{4,6}(4+6) \\
& +\mathrm{y}_{4,7}(4+7)+\mathrm{y}_{5,6}(5+6)+\mathrm{y}_{5,7}(5+7) \\
& +\mathrm{y}_{6,7}(6+7)+\mathrm{y}_{6,9}(6+9)+\mathrm{y}_{7,7}(7+7) \\
& +\mathrm{y}_{7,9}(7+9)+\mathrm{y}_{7,12}(7+12)+\mathrm{y}_{9,9}(9+9) \\
& +\mathrm{y}_{9,12}(9+12)+\mathrm{y}_{12,12}(12+12) \\
= & 7(4)+8(2)+10(4)+11(4)+11(4)+12(2) \\
& +13(12)+15(8)+14(2 \mathrm{~m}+2 \mathrm{n}-10)+16(4 \mathrm{~m} \\
& +4 \mathrm{n}-32)+17(2)+18(2 \mathrm{~m}+2 \mathrm{n}-18)+19(4 \mathrm{~m} \\
& +4 \mathrm{n}-36)+24(3 \mathrm{mn}-14 \mathrm{~m}-14 \mathrm{n}+65)
\end{aligned}
$$

After simplification of terms, we get the required result for TSM sheet

$$
\mathrm{ZC}_{1}^{*}(\mathrm{TSM})=198+72 \mathrm{mn}-124[\mathrm{n}+\mathrm{m}]
$$

Remark: We have the following results for fixed value of $\mathbf{m}$ or $\mathbf{n}$
a) If $\mathrm{m}=4$ and $\mathrm{n} \geq 4$, then
1. $Z_{1}(\mathrm{TSM})=-594+260 \mathrm{n}$
2. $\mathrm{ZC}_{2}(\mathrm{TSM})=-1733+674 \mathrm{n}$
3. $\mathrm{ZC}_{1}^{*}(\mathrm{TSM})=-298+164 \mathrm{n}$
b) If $\mathrm{n}=4$ and $\mathrm{m} \geq 4$ then
1. $\mathrm{ZC}_{1}(\mathrm{TSM})=-594+260 \mathrm{~m}$
2. $\mathrm{ZC}_{2}(\mathrm{TSM})=-1733+674 \mathrm{~m}$
3. $\mathrm{ZC}_{1}^{*}(\mathrm{TSM})=-298+164 \mathrm{~m}$

\section{Theorem 2}

For $\mathrm{n} \geq 3$, the Zagreb connection indices for the cyclic octahedron $\mathrm{CYO}(\mathrm{n})$ are given as:

(1) $\mathrm{ZC}_{1}(\mathrm{G})=256 \mathrm{n}$

(2) $\mathrm{ZC}_{2}(\mathrm{G})=645 \mathrm{n}$

(3) $\mathrm{ZC}_{1}^{*}(\mathrm{G})=176 \mathrm{n}$

\section{Proof}

Total edges are $12 \mathrm{n}$ for $\mathrm{n}$ cycles and total vertices for $n \geq 3$ cycles is $5 n$. Here there are all three different connection numbers $c_{5}, c_{9}$ and $c_{10}$ when the octahedrons are connected in a cycle. The results follows from Table 3 and Table 4 and from Eq. (1-3).

\section{Theorem 3}

Let $\mathrm{AZD}(\mathrm{n})$ be the Aztec diamond. Then,

(1) $\mathrm{ZC}_{1}(\mathrm{G})=128 \mathrm{n}^{2}-184 \mathrm{n}-76$

(2) $\mathrm{ZC}_{2}(\mathrm{G})=256 \mathrm{n}^{2}-504 \mathrm{n}+52$

(3) $\mathrm{ZC}_{1}^{*}(\mathrm{G})=64 \mathrm{n}^{2}-72 \mathrm{n}-36$

\section{Proof}

We know the general connection index is given by $\mathrm{ZC}_{1}(\mathrm{AZD}(\mathrm{n}))=\sum_{0 \leq \mathrm{i} \leq \mathrm{n}-2} \mathrm{C}_{\mathrm{i}}(\mathrm{AZD}(\mathrm{n}))^{*}$, and from vertex partition given in Table 5, we have

$$
\begin{aligned}
\mathrm{ZC}_{1}(\mathrm{AZD}(\mathrm{n}))= & \mathrm{c}_{3} 3^{2}+\mathrm{c}_{4} 4^{2}+\mathrm{c}_{5} 5^{2}+\mathrm{c}_{7} 7^{2}+\mathrm{c}_{8} 8^{2} \\
= & 4.3^{2}+8.4^{2}+(8 \mathrm{n}-20) 5^{2}+4.7^{2} \\
& +\left(2 \mathrm{n}^{2}-6 \mathrm{n}+1\right) 8^{2}
\end{aligned}
$$

After simplification of terms, we get:

$\mathrm{ZC}_{1}(\mathrm{AZD}(\mathrm{n}))=128 \mathrm{n}^{2}-184 \mathrm{n}-76$

Table 3. Partition of the vertex set of CYO(n)

\begin{tabular}{ll}
\hline Vertices of type $c_{i}$ & Number of vertices \\
\hline$c_{5}$ & $3 \mathrm{n}$ \\
$c_{9}$ & $\mathrm{~N}$ \\
$\mathrm{c}_{10}$ & $\mathrm{~N}$ \\
\hline
\end{tabular}

Table 4. Partition of the edge set of $\mathrm{CYO}(\mathrm{n})$

\begin{tabular}{ll}
\hline Edges of type $\mathrm{y}_{\mathrm{i}, \mathrm{j}}(\mathrm{CYO}(\mathrm{n}))$ & No. of edges \\
\hline $\mathrm{y}_{5,5}$ & $3 \mathrm{n}$ \\
$\mathrm{y}_{5,9}$ & $2 \mathrm{n}$ \\
$\mathrm{y}_{5,10}$ & $4 \mathrm{n}$ \\
$\mathrm{y}_{9,10}$ & $2 \mathrm{n}$ \\
$\mathrm{y}_{10,10}$ & $\mathrm{n}$ \\
\hline
\end{tabular}


All the vertices with their respective connection numbers are given in Table 5 .

For the indices $\mathrm{ZC}_{2}(\mathrm{AZD}(\mathrm{n}))$ and $\mathrm{ZC}_{1}^{*}(\mathrm{AZD}(\mathrm{n}))$, we need to partition the edges of the $\mathrm{AZD}(\mathrm{n})$ according to the connection numbers of the end points of an edge. It is easy to see that all the edges labelled with their connection number are given in Table 6.

Table 5. Partition of vertex set of Aztec diamond

\begin{tabular}{ll}
\hline Vertices of type $c_{i}$ & Number of vertices \\
\hline$c_{3}$ & 4 \\
$c_{4}$ & 8 \\
$c_{5}$ & $8 n-20$ \\
$c_{7}$ & 4 \\
$c_{8}$ & $2 n^{2}-6 n+1$ \\
\hline
\end{tabular}

Table 6. Partition of edge set of Aztec diamond AZD(n)

\begin{tabular}{ll}
\hline Edges of type $\mathrm{y}_{\mathrm{i}, \mathrm{j}}(\mathrm{AZD}(\mathrm{n}))$ & No. of edges \\
\hline $\mathrm{y}_{3,4}$ & 8 \\
$\mathrm{y}_{3,7}$ & 4 \\
$\mathrm{y}_{4,5}$ & 8 \\
$\mathrm{y}_{5,5}$ & $8 \mathrm{n}-24$ \\
$\mathrm{y}_{5,7}$ & 8 \\
$\mathrm{y}_{5,8}$ & $8 \mathrm{n}-24$ \\
$\mathrm{y}_{7,8}$ & 4 \\
$\mathrm{y}_{8,8}$ & $4 \mathrm{n}^{2}-16 \mathrm{n}+12$ \\
\hline
\end{tabular}

From the last column of the table we can verify by adding up all the edges to get the total number of edges for all the $\operatorname{AZD}(n)=4 n^{2}-4$. Also, the restriction is $n \geq 4$ to compute the Zagreb connection index $\mathrm{ZC}_{2}(\mathrm{AZD}(\mathrm{n}))$ and $\mathrm{ZC}_{1}{ }^{*}(\mathrm{AZD}(\mathrm{n}))$. Here using the formula in Eq. (2) and on the last column for all edges in Table 6, we have

$$
\begin{aligned}
& \mathrm{ZC}_{2}(\mathrm{AZD}(\mathrm{n}))= \mathrm{y}_{3,4}(3)(4)+\mathrm{y}_{3,7}(3)(7)+\mathrm{y}_{4,5}(4)(5) \\
&+\mathrm{y}_{5,5}(5)(5)+\mathrm{y}_{5,7}(5)(7)+\mathrm{y}_{5,8}(5)(8) \\
&+\mathrm{y}_{7,8}(7)(8)+\mathrm{y}_{8,8}(8)(8) \\
&=12(8)+21(4)+ 20(8)+25(8 \mathrm{n}-24)+35(8)+40(8 \mathrm{n}-24) \\
&+56(8)+64\left(4 \mathrm{n}^{2}-16 \mathrm{n}+12\right)
\end{aligned}
$$

After simplification of terms, we get the required formula $\mathrm{ZC}_{2}(\mathrm{G})=256 \mathrm{n}^{2}-504 \mathrm{n}+52$

From Eq. (3) and Table 6 we have the followings:

$$
\begin{aligned}
Z_{1}^{*}(\operatorname{AZD}(n)) & =\sum_{0 \leq \mathrm{i} \leq \mathrm{n}-2} \mathrm{y}_{\mathrm{i}, \mathrm{j}}(\operatorname{AZD}(\mathrm{n}))^{*}(\mathrm{i}+\mathrm{j}) \\
& =\mathrm{y}_{3,4}(3+4)+\mathrm{y}_{3,7}(3+7)+\mathrm{y}_{4,5}(4+5)
\end{aligned}
$$

$$
\begin{aligned}
& +y_{5,7}(5+7)+y_{5,5}(5+5)+y_{5,8}(5+8) \\
& +y_{7,8}(7+8)+y_{8,8}(8+8) \\
= & 7(8)+10(4)+9(8)+10(8 n-24)+12(8) \\
& +13(8 n-24)+15(8)+16\left(4 n^{2}-16 n+12\right) \\
= & 64 n^{2}-72 n-36
\end{aligned}
$$

Similarly, we can obtained the Zagreb connection indices for Aztec diamond $\operatorname{EAZD}(\mathrm{n})$ in the following theorem.

\section{Theorem 4}

The Zagreb connection indices for extended Aztec diamond $\operatorname{EAZD}(\mathrm{n})$ are follows;

(1) $\mathrm{ZC}_{1}(\operatorname{EAZD}(\mathrm{n}))=128 \mathrm{n}^{2}+264 \mathrm{n}-492$

(2) $\mathrm{ZC}_{2}(\operatorname{EAZD}(\mathrm{n}))=256 \mathrm{n}^{2}+524 \mathrm{n}-1168$

(3) $\mathrm{ZC}_{1}^{*}(\operatorname{EAZD}(\mathrm{n}))=64 \mathrm{n}^{2}+160 \mathrm{n}-204$

\section{- CONCLUSION}

In this paper, we computed some topological indices of Tickysim SpiNNaker model TSM, cyclic octahedral structure, Aztec diamond $\operatorname{AZD}(n)$ and extended Aztec diamond EAZD(n). The obtained results can be used to predict the certain physio- chemical properties of a molecule as these indices are functions of chemical graphs and can encode many chemical properties such as entropy, boiling point, acentric factor and enthalpy of vaporization. As cited earlier $\mathrm{ZC}_{1}$ has a very good correlation with physical properties, mainly with the standard enthalpy of vaporization and having a better correlation than the Wiener Index [12]. The Fig. 5 , we can take note that all indices raise sharply with $n$ (since all indices are quadratic in terms of order). But the $\mathrm{ZC}_{2}$ is greater than all other leap indices. Similarly, $\mathrm{ZC}_{1}{ }^{*}$ correlates well with the acentric factor and entropy and from Fig. 6, we see a similar observation having is predicted to have comparatively much higher values for their eccentric factor with again the former having much larger values than the latter.

It is notable that the obtained results for closed formulas for these networks are all quadratic in terms of order which show that one can build efficient graph algorithms to compute the indices within polynomial time. 


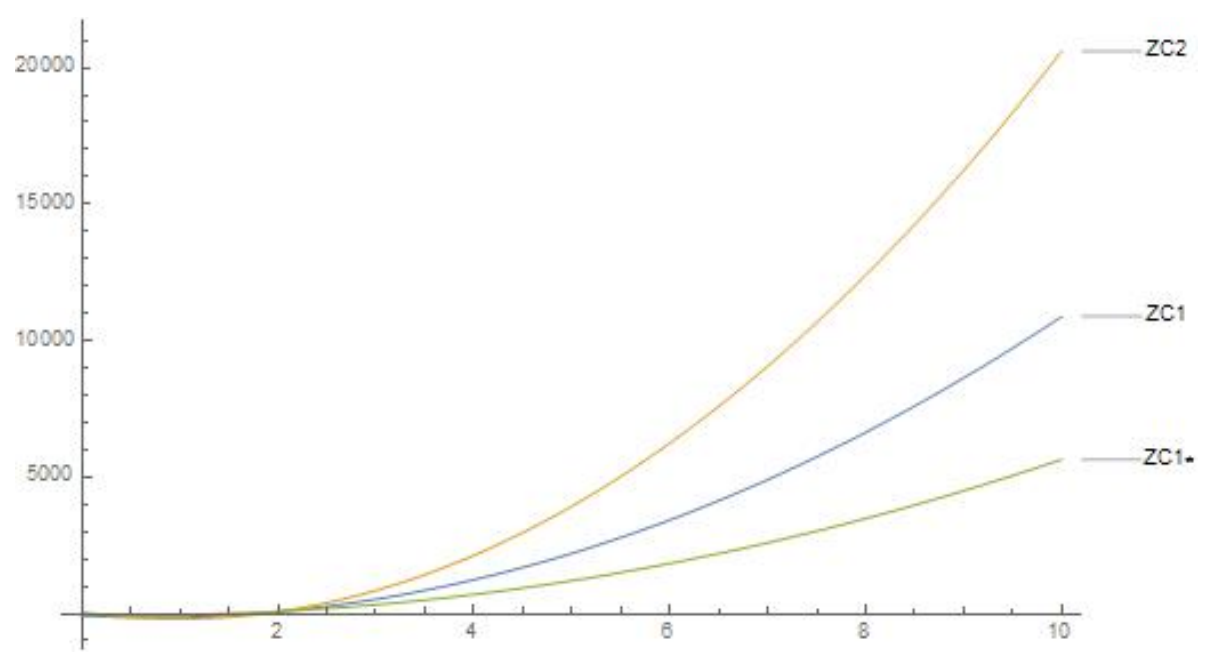

Fig 5. Leap indices for Aztec diamond AZD(n)



Fig 6. Leap indices for TSM

\section{- ACKNOWLEDGMENTS}

Zahid Raza has been funded during the work on this paper by the University of Sharjah under Project \# 1802144068 and MASEP Research Group.

\section{- REFERENCES}

[1] Gutman, I., and Trinajstić, N., 1972, Graph theory and molecular orbitals. Total $\varphi$-electron energy of alternant hydrocarbons, Chem. Phys. Lett., 17 (4), $535-538$.
[2] Imran, M., Baig, A.Q., Siddiqui, H.M.A., and Sarwar, R., 2017, On molecular topological properties of diamond-like networks, Can. J. Chem., 95, 758-770.

[3] Imran, M., Siddiqui, H.M.A., Ahmed, A., Ali, U., and Hanif, N., 2018, On the degree-based topological indices of the Tickysim SpiNNaker model, Axioms, 73 (4), 73.

[4] Stojmenovic, I., 1997, Honeycomb networks: Topological properties and communication 
algorithms, IEEE Trans. Parallel Distrib. Syst., 8 (10), 1036-1042.

[5] Zahid, M.A., Baig, A.Q., Naeem, M., and Azhar, M.R., 2018, Eccentricity-based topological indices of a cyclic octahedron structure, Mathematics, 6 (8), 141.

[6] Khalid, R., Idrees, N., and Saif, M.J., 2019, Topological characterization of book graph and stacked book graph, CMC-Comput. Mater. Con., 60 (1), 41-54.

[7] Li, M.Y., and Sevov, S.C., 2013, Mellitate-based coordination polymers with a recurring motif: Controlling dimensionality with secondary ligands, CrystEngComm, 15 (25), 5107-5113.

[8] Perry IV, J.J., Perman, J.A., and Zaworotko, M.J., 2009, Design and synthesis of metal-organic frameworks using metal-organic polyhedra as supermolecular building blocks, Chem. Soc. Rev., 38 (5), 1400-1417.

[9] Gutman, I., Rui, B., Trinajstić, N., and Wilcox Jr., C.F., 1975, Graph theory and molecular orbitals. XII. Acyclic polyenes, J. Chem. Phys., 62 (9), 3399.

[10] Ali, A., and Trinajstić, N., 2018, A novel/old modification of the first Zagreb index, Mol. Inf., 37 (6-7), 1800008.

[11] Naji, A.M., Soner, N.D., and Gutman, I., 2017, On leap Zagreb indices of graphs, Commun. Comb. Optim., 2 (2), 99-117.

[12] Basavanagoud, B., and Jakkannavar, P., 2018, Computing first leap Zagreb index of some nano structures, Int. J. Math. Appl., 6 (2B), 135-139.

[13] Khalid, K., Kok, I., Ali, A., and Bashir, M., 2019, Zagreb connection indices of $\mathrm{TiO}_{2}$ nanotubes, Khimiya, 27 (1), 86-92.
[14] Ducoffe, G., R. Marinescu-Ghemeci, R., Obreja, C., Popa, A., and Tache, R., 2018, Extremal graphs with respect to the modified first Zagreb connection index, Proceedings of the $16^{\text {th }}$ Cologne-Twente Workshop on Graphs and Combinatorial Optimization (CTW18), Paris, France, 18-20 June 2018, 02011265.

[15] Basavanagoud, B., and Jakkannavar, P., 2018, Computing leap Zagreb indices of generalized xyz point-line transformation graphs $T^{x y z}(G)$ when $z=$ +, J. Comput. Math. Sci., 9 (10), 1360-1383.

[16] Noreen, S., Bhatti, A.A., and Ali, A., 2020, Extremum modified first Zagreb connection index of n-vertex trees with fixed number of pendent vertices, Discrete Dyn. Nat. Soc., 2020, 3295342.

[17] Noreen, S., Bhatti, A.A., and Ali, A., 2020, Extremal trees for the modified first Zagreb connection index with fixed number of segments or vertices of degree 2, J. Taibah Univ. Sci.,14 (1), 31-37.

[18] Raza, Z., 2020, The harmonic and second Zagreb indices in random polyphenyl and spiro chains, Polycyclic Aromat. Compd., 0 (0), 1-10.

[19] Raza, Z., and Sukaiti, M.E., 2020, M-Polynomial and degree based topological indices of some nanostructures, Symmetry, 12 (5), 831.

[20] Raza, Z., 2016, The edge version of geometric arithmetic index of polyomino chains of 8-cycles and arbitrary carbon nanocones, J. Comput. Theor. Nanosci., 13 (11), 8455-8459.

[21] Ali, U., Javaid, M., and Kashif, A., 2020, Modified Zagreb connection indices of the T-sum graphs, Main Group Met. Chem., 43, 43-55. 